\title{
A Review on Ergonomics Risk Factors and Health Effects Associated
} with Manual Materials Handling

\author{
Al Amin MS ${ }^{1, a}$, Nuradilah $Z^{2, b}$, Isa $H^{3, c}$, Nor Akramin $M^{4, d}$, Febrian I, \\ and Taufik \\ $6, f$ \\ 1,2,3,4,5,6 Universiti Teknikal Malaysia Melaka (UTeM), Hang Tuah Jaya, 76100, Durian Tunggal, \\ Melaka, Malaysia.

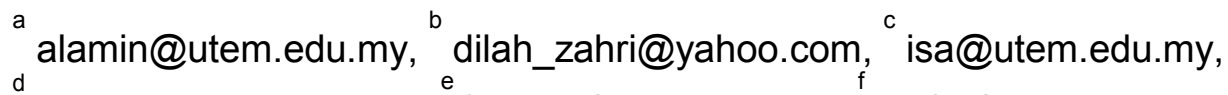 \\ dakramin@utem.edu.my, febrian@utem.edu.my, taufik@utem.edu.my
}

Keywords: Manual materials handling, ergonomics risk factors, health effects.

\begin{abstract}
In the industrial workplaces, manual materials handling is a necessity for the workers. However, improper materials handling technique can contribute to occupational injuries. The objective of this paper is to provide information on ergonomics risk factors and health effects associated with manual materials handling. Ergonomics risk factors include awkward posture, excessive load, and extreme temperature has been identified as main contributors to poor occupational health in manual materials handling activities.
\end{abstract}

\section{Introduction}

Materials handling can be defined as handling, moving, lifting, lowering or carrying equipment, materials or goods from one place to another either by using supporting equipment or hand [1]. In the industry, manual materials handling such as lifting is commonly practiced even though the materials handling facilities are equipped with advanced technology. The reason is that 10 percent of the task in the industry required extensive manual materials handling [2].

In manufacturing industry, manual materials handling activities such as lifting, holding, and lowering are highly demanded in order to accomplish a task. Lifting can be defined as the act of manually grasping an object of definable size and mass with one or two hands, and vertically moving the object without assistive devices [3]. Lifting techniques include diagonal lift, power lift, tripod lift, partial squat lift, golfer's lift, straight leg lift, overhead lift and pivot technique [4]. Holding is an action that maintains a grasp or grip on the object [5]. People can hold the object in various ways such as; by holding the loads with one hand at waist, two hands at waist, one hand at side, two hands at side, and one or two hands at overhead [6]. Lowering is an action where people are required to lower their bodies to lift the objects or lowering the loads from the knuckle height [7]. The activities of lifting, holding and lowering can be found everywhere, for instance, a storekeeper lift, hold, and lower the liquid petroleum gas tank while delivering it to customer [8].

Manual materials handling has been hypothesized as an essential way for worker to perform tasks in industry, however it was found to be harmful if it is improperly conducted. The objective of this paper is to review ergonomic risk factors related to manual materials handling activities and its implications to the worker.

\section{Ergonomics Risk Factor in Manual Materials Handling}

Based on literature review, this study identified three ergonomic risk factors associated with manual materials handling. Those ergonomics risk factors are described in the following section.

\section{Awkward working posture}

Working posture can be defined as the orientation of body segments in a work space and in relation to each other while a worker is performing a task [9]. Posture includes aspect of angular relation and the distribution mass of the body parts. Postures are affected due to the factors such as 
exerted force and length of time held [10]. Manual materials handling involves muscle activity in static and dynamic works. Static work is a condition of a person maintaining their posture, while dynamic work is a condition of active skeletal muscles contracting and relaxing rhythmically [11]. Awkward working posture occurred when the worker is required to accomplish a task in unnatural posture such as twisting, bending, stretching and reaching due to poor workstation design and job process. For example, an obstruction at a workstation forces the worker's back into flexion state that causes the object to move away from the spine and increases the load on the spine [1]. Poor working posture influenced the activation of muscle and tends to stress the muscle [12].

Muscle activities increase, whenever there is an increase in shoulder flexion which affected pectoralis major and inferior trapezius muscle [13]. Meanwhile, a study found that forward head posture as well as shoulder flexion contributes to stressful high muscle activities in the upper trapezius and lower trapezius [14]. Working in a posture with hand positions above $100 \%$ of shoulder's height causes a person to feel discomfort in the shoulder and arm [15]. The potential of getting injuries increases when the workers are required to perform manual material handling in an unstable position such as working in an uneven walking surface. Lifting loads in slope surfaces may strain the back. Besides, posture is also related to the length of time held where a posture can be maintained for a limited period of time. The maximum holding time is the maximum period of a posture can last with or without external force exerted can be maintained continuously until maximum discomfort is experienced from a rested state [15]. Injuries may increase if the workers are exposed to the strength exertion force and exceeded endurance time [16]. However, by considering the rest time while working, the potential of getting injuries can be minimized [17].

\section{Excessive load}

Handling heavy loads manually whether by lifting, holding and lowering had greater potential to injuries. Heavy load may lead the contacted muscles to experience overexertion. The high muscle load is one of the factors that cause muscle fatigue [18]. Furthermore, pressure also applied to the muscle in the situation of holding and carrying heavy loads. It has been proved that holding the loads on the shoulder resulting in increased of pressure and pain on the loaded muscle [19].

\section{Extreme temperature}

Extreme working environment can cause the workers discomfortness while performing manual materials handling and may lead to fatigue [20]. A study proved that when workers are performing manual materials handling associated with carrying task in a hot working environment, they experienced discomfort and fatigue [21]. Muscle fatigue occurred due to increasing of lactate and inorganic phosphate in the muscle and positively induced muscle force [22]. Working in extreme cold or hot temperature may increase low back symptoms [23, 16]. Meanwhile, a study investigates the effect of holding loads in an extreme cold temperature which result in cold stress [24]. Cold stress will lead to muscle rigidity and circulation problems [25]. In addition, loading work in severely cold environment for prolonged period leads to reduction in manual dexterity and increased risk of accidents [26]. Besides, it also causes the flexibility of muscle and joints decrease and may increase the likelihood of musculoskeletal injuries [27].

\section{Health Effects due to Manual Material Handling}

In manual materials handling, the ergonomic risk factors discussed in the previous section can contribute to occupational injuries to workers. Manual handling of loads such as transporting or supporting the loads in an unfavorable ergonomic condition might expose the workers to particular risks and back injuries [28]. Two groups of injuries may result from manual handlings which are cuts, bruises and fractures due to accidents; and musculoskeletal injuries [11]. Musculoskeletal injuries affect muscles, tendons, ligaments, joints, nerves, blood vessels or related soft tissues due to awkward postures, repetitive motions, and forceful exertions [29]. 
Improper manual materials handling can increase the likelihood of musculoskeletal injuries. As consequences of the injuries, the performance of workers such as productivity and quality may decrease [2]. Most of the workers complaints of having fatigue, back pain, upper body and neck pain and hand or arm soreness due to manual materials handling. In addition, it is also reported that $70 \%$ of injuries are affecting back and shoulders thus prevent the workers to perform their task in the workplace [29]. A study proved that there is a significant effect to L5/S1 due to working in a condition which is facing uphill [23]. Workers had suffered from pain in the back, shoulder, neck, headache due to poor posture with high velocity, motion repetitiveness, bending and twisting [8, 30]. Fatigue and pain in the shoulder occurred due to the flexion, holding weight and increase in holding duration [31, 32]. Local muscle fatigue is a result of a growth of intramuscular pressure and decreased blood flow in upper limb muscles with arm elevation. Whenever the muscle blood flows is restricted, it impairs muscle metabolisms and increases metabolite accumulation, hence resulting in muscle fatigue.

\section{Opportunities for Future Study}

In recognition of the importance of managing manual materials handling, there were several research works that have been conducted. Table 1 provides information on manual materials handling techniques, method used to perform the study and parameters considered in the experimental works. Based on the table, this study pointed out that many research works focused on manual materials handling associated with holding, lifting, and lowering. Methods used were subjective assessment (e.g. Borg scale) and direct technical measurement (e.g. surface electromyography). Additionally previous research works investigated several parameters such as working posture, load mass, temperature, task frequency, walking surface, rest time and exposure time.

Based on Table 1, there is a need to study the effects of load mass, walking surface and holding time on psychophysical experience and muscle activity. Currently, there is minimal study related to holding task been conducted in Malaysia. Thus, future study is required to investigate the impact of the parameters to Malaysian workers while they are performing a holding task. Psychophysical experience is a subjective method that used to assess subjective feedbacks, complaints and discomforts levels while performing physical works [34]. Meanwhile, direct technical measurement method such as measurement of muscle activity and pressure can be carried out using technical instruments which produce specific quantities such as frequencies and forces [35]. Muscle fatigue due to holding task can be measured by observing the changes in amplitude and frequency of electromyogram signals that indicate the muscle activities [36]. Besides, pressure sensors can be used to quantify the distribution of force and pressure on the body parts [37]. Further statistical analysis could be carried out to generate mathematical models to predict the effects of load mass, walking surface and holding time on psychophysical experience, pressure and muscle activity.

Table 1: Research works, methods used, and studied parameters in manual materials handling

\begin{tabular}{|c|c|c|c|c|c|c|c|c|c|c|c|c|}
\hline \multirow{2}{*}{\begin{tabular}{|l} 
Research \\
works
\end{tabular}} & \multicolumn{3}{|c|}{ Materials handling techniques } & \multicolumn{2}{|c|}{ Methods } & \multicolumn{7}{|c|}{ Parameters } \\
\hline & Holding & Lifting & Lowering & Subjective & Technical & Posture & \begin{tabular}{|l} 
Load \\
Mass
\end{tabular} & Temperature & \begin{tabular}{|l} 
Task \\
frequency
\end{tabular} & $\begin{array}{l}\text { Walking } \\
\text { surface }\end{array}$ & \begin{tabular}{|l}
$\begin{array}{l}\text { Rest } \\
\text { time }\end{array}$ \\
\end{tabular} & \begin{tabular}{|l} 
Exposure \\
time
\end{tabular} \\
\hline [5] & $\beta$ & & & & $\beta$ & $\beta$ & $\beta$ & & & & & \\
\hline [7] & & 急 & F & & $\beta$ & $\beta$ & F & & & & & \\
\hline [8] & B & $\beta$ & $\beta$ & & $\beta$ & $\beta$ & & & & & $\beta$ & $\beta$ \\
\hline [15] & $\beta$ & & & F & & $\beta$ & & & & & & B \\
\hline [17] & & po & Fo & & & $\beta$ & F & & & & $\beta$ & \\
\hline [23] & & po & & & & & $\beta$ & & & p & & \\
\hline [24] & $\beta$ & F & & & F & & F & F & & & Fo & B \\
\hline [31] & $\beta$ & & & $\beta$ & & $\beta$ & F & & F & & & $\beta$ \\
\hline [33] & B & $\beta$ & $\beta$ & & $\beta$ & & F & & & F & & \\
\hline $\begin{array}{l}\text { Future } \\
\text { Study }\end{array}$ & $\beta$ & & & $\beta$ & $\beta$ & & F & & & F & & $\beta$ \\
\hline
\end{tabular}




\section{Conclusion}

This paper has performed a literature review on ergonomics risk factors and health effects associated with manual materials handling. This paper concluded that ergonomics risk factors such as awkward working posture, excessive load, and extreme temperature can contribute to poor occupational health in manual materials handling. The workers may suffer from occupational injuries such as back pain, shoulder pain, and muscle fatigue due to improper manual materials handling. This paper suggests that manual materials handling parameters such as load mass, holding time and walking surface require further analysis so that a mathematical model could be generated to predict the impact of those parameters on occupational health.

\section{Acknowledgment}

The authors would like to acknowledge the Universiti Teknikal Malaysia Melaka (UTeM) for funding this research under University Short Term Grant (PJP/2012/FKP (7D) S1126) and the Faculty of Manufacturing Engineering (UTeM) for providing facilities in carrying out this study. In this opportunity, the authors would like to thanks Mr. Mohamad Tahkim bin Salahudin for his co operation.

\section{References}

[1] C.Berie, A.McNeely, K.Beauregard, J.E.Geddie, A Guide to Manual Materials Handling and Back Safety, Occupational Safety and Health, N.C Department of Labor, 2009.

[2] Workers Health and Safety Division, Manual Material Handling: An Ergonomic Approach, Texas Workers' Compensation Commission, (nd).

[3] Ergonomic Guidelines for Manual Material Handling, Cal/OSHA Consultation Service, Research and Education Unit, Division of Occupational Safety and Health, California Department of Industrial Relation,(2007).

[4] U.S Army Center for Health Promotion and Preventive Medicine, Ergonomics Program, "Lifting Technique",(nd).

[5] A.G.Witney, D.M.Wolpert, The Effect of Externally Generated Loading on Predictive Grip Force Modulation, Neuroscience Letters, Vol.414, Iss.1 (2007) 10-15.

[6] M.A.Holbein and M.S.Redfern, Functional Stability Limits While Holding Loads in Various Positions, International Journal of Industrial Ergonomics 19 (1997) 387-395.

[7] C.M.Mckean and J.R Potvin, Effecs of a Simulated Industrial Bin on Lifting and Lowering Posture and Trunk Extensor Muscle Activity, International Journal of Industrial Ergonomics, Vol.28, Iss.1 (2001) 1-15.

[8] S.S.Chowdhury, J.Boricha and S.Yardi, Identification of Awkward Postures That Cause Discomfort to Liquefied Petroleum Gas Workers in Mumbai, India, Indian Journal of Occupational \&Environmental Medicine, Vol.16, Iss.1(2012) 3-8.

[9] Bridger RS, Introduction to Ergonomics. 2nd ed. London: Taylor \& Francis (2003) 33.

[10] S.May, Posture the Lumbar Spine and Back Pain, International Encyclopedia of Rehabilitation (2010).

[11] Hazards and Risks Associated with Manual Handling in the Workplace, European Agency for Safety and Health at Work; available at http://osha.europa.eu.

[12] E.P.Takala, S.Lammi, H.Nieminen and E.V.Juntura, Electromyographic Changes in the Static Holding Test Of The Arm, International Journal of Industrial Ergonomics, Vol. 12, Iss.1-2 (1993) $85-90$. 
[13] R.L.Brookham, J.M,Wong and C.R.Dickerson, Upper limb Posture and Submaximal Hand Tasks Influence Shoulder Muscle Activity, International Journal of Industrial Ergonomics 40 (2010) 337-344.

[14] J.Weon, J.Oh, H.Cynn, Y.Kim, O.Kwon and C.Yi, Influence of Forward Head Posture on Scapular Upward Rotators during Isometric Shoulder Flexion, Journal of Bodywork and Movement Therapies (2009).

[15] M.C.Miedema, M.Douwes and J.Dul, Recommended Maximum Holding Time for Prevention of Discomfort of Static Standing Postures, International Journal of Industrial Ergonomics 19 (1997) 9-18.

[16] B.Widanarko, S. Legg, M. Stevenson, J. Devereux, A. Eng, A. Mannetje, S. Cheng and N. Pearce, Prevalence And Work-Related Risk Factors for Reduced Activities and Absenteeism Due to Low Back Symptoms, Applied Ergonomics 43 (2012) 727-737.

[17] H.Shin and J.Kim, Measurement of Trunk Muscle Fatigue During Dynamic Lifting and Lowering as Recovery Time Changes, International Journal Of Industrial Ergonomics, Vol. 37, Iss.6 (2007) 545-551.

[18] D.B.Chaffin and G.B.J.Anderson, Occupational Biomechanics, Wiley Interscience (1999).

[19] A.L.Persson, G.A.Hansson, A.Kalliomaki, U.Moritz, and B.H.Sjolund, Pressure Pain Threshold and Electromyographically Defined Muscular Fatigue Induced by a Muscular Endurance Test in Normal Women, Clin. J. Pain (2000) 155-163.

[20] A Health and Safety Guidelines for Your Workplace, Manual Materials Handling, Indusrial Accident Prevention Association (2008); available at www.iapa.ca.

[21] A.Batish, T.P.Singh, MHAC-An Assessment Tool for Analysing Manual Material Handling Tasks, International Journal of Occupational Safety and Ergonomics, Vol.14, No. 2 (2008) 223-235.

[22] S.Ueno, K.Yokohama, M.Nakagawa and S.Araki, Effects of $\mathrm{pH}$ and Temperature on Force and Stiffness of Skeletal Muscle Fibers during Contraction and Relaxation in Relation to Musculoskeletal Disorders, Industrial Health, Vol.40 (2002) 362-369.

[23] R.F.Reiser, E.E.Wickel and H.M.Menzer, Lumbar Mechanics of Floor to Knuckle Height Lifting on Sloped Surfaces, International Journal Of Industrial Ergonomics, Vol.38, Iss.1 (2008) 47-55.

[24] T.Kim, Y.Tochihara, M.Fujita and N.Hashiguchi, Physiological Responses and Performance of Loading Work in a Severely Cold Environment, International Journal of Industrial Ergonomics 37 (2007) 725-732.

[25] J. Berrigan, Ergonomics, Environmental/Occupational Health and Safety Office, (2010).

[26] S.Powell, A.Davies, J.Bunn and D.Bethea, The Effects of Thermal Environments on the Risk Associated with Manual Handling, Health and Safety Executive (2005).

[27] Manual Material Handling-Health Hazards, Canadian Center for Occupational Health and Safety (2009); available at www.ccohs.ca.

[28] Guidance on the Management of Manual Material Handling in the Workplace, Health and Safety Authority, 10 Hogan Place, Dublin 2 (2005).

[29] Ergonomics Guidelines For Manual Material Handling,WorksafeNB (2010). [30] W.C.Shiel, Shoulder and Neck Pain; available at: http://www.emedicinehealth.com/shoulder_and_neck_pain/ page3_em. htm\# shoulder_and_neck_pai n_symptoms_and_signs.

[31] C.L.Lin, M.J.Wang, C.G.Drury and Y.Chen, Evaluation of Perceived Discomfort in Repetitive Arm Reaching and Holding Task, International Journal of Industrial Ergonomics 40 (2010) 90-96. 
[32] A.Garg, K.T.Hegmann, B.J.Schwoerer and J.M.Kapellusch, The Effect of Maximum Voluntary Contraction on Endurance Time for The Shoulder Girdle, International Journal of Industrial Ergonomics, Vol.30, Iss.2 (2002) 103-113.

[33] S.Matsuda, T.Ishinishi and L.A.Whiteside, Contact Stresses with an Unresurfaced Patella in Total Knee Arthroplasty: The Effect of Femoral Component Design, Orthopedics Vol.23 Iss.3 (2000) 213-218.

[34] G.Borg, Psychophysical Scalling with Applications in Physical Work and the Perception of Exertion, Scandinavian Journal of Work, Environment and Health, 16 (1990) 55-58.

[35] I.Halim, A.R. Omar, A. M. Saman, I. Othman and M.A. Ali: Development of a Questionnaire for Prolonged Standing Jobs at Manufacturing Industry, Advances in Human Factors, Ergonomics, and Safety in Manufacturing and Service Industries (2010) 253-263.

[36] I.Hostens and H.Ramon, Assessment of Muscle Fatigue in Low Level Monotonous Task Performance during Car Driving, Journal of Electromyography and Kinesiology, 15 (2005) 266274.

[37] H.J.Agins, V.S. Harder, E.P.Lautenschlager and J.C.Kudrna, Effects of Sterilization on the Tekscan Digital Pressure Sensor, Medical Engineering and Physics (2003). 